\title{
MRS honors outstanding contributions to materials research at 2018 MRS Fall Meeting
}

The MRS Awards Program strives to acknowledge outstanding contributors to the progress of materials research and to recognize their exciting and profound accomplishments. We seek to honor those whose work has already had a major impact in the field, who have defined the frontiers of the field, who are outstanding exponents of their science, and young researchers whose work already leads to great expectations for future leadership.

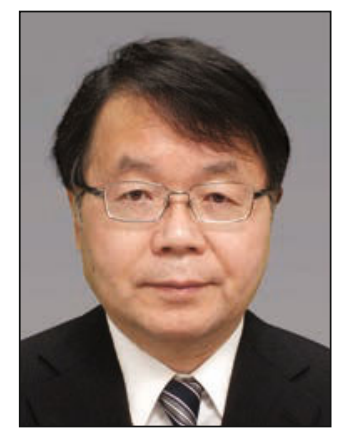

\section{Hideo Hosono to receive 2018 Von Hippel Award}

$\mathrm{T}$ 2018 Von Hippel Award, the Materials Research Society's (MRS) highest honor, will be presented to Hideo Hosono from the Tokyo Institute of Technology. Hosono is being recognized "for the discovery of high Tc iron-based superconductors, creation of transparent oxide semiconductors and inorganic electrides." Hosono will present his award talk, "Element Strategy in Materials Research," at the 2018 MRS Fall Meeting in Boston on Wednesday, November 28, at 6:15 pm, in the Grand Ballroom of the Sheraton Boston Hotel.

Currently a professor at the Laboratory for Materials and Structures at the Tokyo Institute of Technology, Hosono has cultivated the electroactive functionality of inorganic materials for 20 years, creating several extremely innovative materials, opening up academic fields and large industrial applications. Exploring magnetic semiconductors based on the $p$-type transparent semiconductors $\mathrm{LaCuOCh}$, Hosono discovered the first iron-based superconductor (IBSC) LaFeOP and then the high-Tc $\mathrm{LaFeAsO}_{1-x} \mathrm{~F}_{x}$. His discovery led to extensive research globally, and his group has led materials research on IBSCs.

Hosono created new transparent oxide semiconductors based on the design concept represented by high mobility transparent oxide semiconductors (TAOS) and $p$-type semiconductors. Thin-film transistors of InGaZnO (called IGZO), a member of TAOS, are now applied to drive the pixels of OLED-TVs and highresolution LCD panels.
He synthesized the first roomtemperature stable electride based on the inorganic crystal $12 \mathrm{CaO} \cdot 7 \mathrm{Al}_{2} \mathrm{O}_{3}$. This discovery demonstrated the hidden potential of abundant elements and led to the establishment of the Japan Science \& Technology Policy "Element Strategy Initiative.’

Hosono received his bachelor's and $\mathrm{PhD}$ degrees in engineering from the Tokyo Metropolitan University. He has published $\sim 1000$ papers, five books, and has $\sim 90$ registered patents. His international reputation is confirmed from many famous international prizes, including the Imperial Prize and the Japan Academy Prize (the highest academic honor in Japan).

The MRS Von Hippel Award includes a $\$ 10,000$ cash prize, honorary lifetime membership in MRS, and a trophy. Named after Arthur von Hippel (1898-2003), the award recognizes the qualities most prized by materials scientists and engineers-brilliance and originality of intellect, combined with a vision that transcends the boundaries of conventional disciplines, as exemplified by the life of Arthur von Hippel (http:// vonhippel.mrs.org).

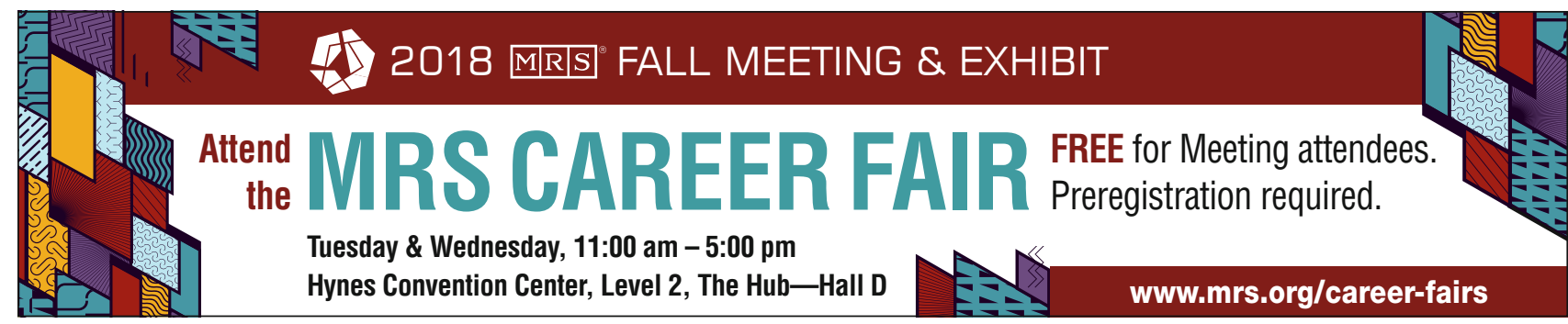

